\title{
Comparative studies in simple oddity learning: I. Cats, raccoons, monkeys, and chimpanzees'
}

\author{
PASCHAL N, STRONG, JR. AND MONNIE hEDGES 2 \\ TEXAS TECHNOLOGICAL COLLEGE
}

Three cats, 3 raccoons, 3 monkeys, and 3 chimpanzees were trained in 1-trial simple oddity problems until criterion was attained or 4800 trials were administered. Identical stimuli and procedures were used with all Ss. It was found that cats and raccoons could not reach criterion while monkeys and chimpanzees did. Chimpanzees were superior to monkeys but the two groups overlapped.

Many organisms have been studied on so called oddity problems but differences in methodology make definitive comparisons difficult. Among organisms investigated have been rats (Koronakos \& Arnold, 1957; Lashley, 1938; Woodinsky \& Bitterman, 1953), canaries (Pastore, 1954), cats (Warren \& Boyd, 1957; Warren, 1960), monkeys (Robinson, 1933; Moon \& Harlow, 1955; Levine \& Harlow, 1959), chimpanzees (Nissen \& McCulloch, 1937; Davenport \& Menzel, 1960), and children (Bromer, 1940; Ellis \& Sloan, 1959; Martin \& Blum, 1960; Martin \& Blum, 1961).

Differences in methodology can be shown in several areas: (1) Total number of stimulus objects used in a study have varied from three (Gardner \& Nissen, 1948) to 352 (Braun, 1952). (2) The number of simultaneously presented objects has varied from three (Robinson, 1933) to 12 (Nissen \& McCulloch). (3) The number of successive trials per problem has varied from one (Strong, 1965) to 12 (Levine \& Harlow, 1959) and in some cases the same problem was presented until learned (Robinson, 1933).

Besides the differences in methodology, various investigators differ in their criterion for the attainment of oddity learning. If an experimenter presents three objects, two identical and one different ( $A A B$ ) for a number of trials it is difficult to tell if the animal is learning oddity or object discrimination. Improvement over problems may merely indicate learning set for object quality discrimination and only a high first trial percent correct on new problems indicates true oddity learning. Strong's study (1965) clearly indicates that presenting the same stimulus configuration for a number of consecutive trials actually impairs the learning of oddity and that one trial presentations seem to be most efficient.

In view of the above, the purpose of the present study was to use highly similar procedures in testing the ability of certain organisms to attain the oddity concept. Attainment of oddity learning was defined as reaching a criterion of $90 \%$ correct or better on one trial oddity and responding at this criterion level to new stimulus configurations when first presented.

\section{Subjects}

Three adult cats, three adult raccoons, three adolescent rhesus monkeys, and three adolescent chimpanzees were used in the study.

Apparatus

A modified WGTA was used for all organisms. The WGTA used with the cats and raccoons was somewhat smaller than that used for the monkeys but similar in all important respects. The chimpanzees were loosely restrained in a training chair and not in a cage section of a WGTA.

Pre Training

All animals were adapted to the WGTA and then taught to displace a single wooden object in order to obtain a reward. Cats and raccoons were rewarded with Friskies, a commercial cat treat while the monkeys and chimpanzees were rewarded with rasins and bits of apples.

Stimuli

The stimuli and testing procedures were identical to the one trial WGTA procedures used by Strong (1965). Stimuli were three dimensional wood objects mounted vertically on black wooden bases. Nine objects were combined in all 72 possible configurations of simple oddity problems (AAB and $A B B$ are considered different configurations). Animals were given 48 trials a session and six different random series of problems were prepared with right and left choices evened out. Each stimulus configuration was presented nonconsecutively although a given stimulus configuration might appear later in the series. The odd object never appeared in the middle position. Animals were run until they attained a criterion of $90 \%$ correct on a given session or until they had had 100 sessions (4800 trials).

After criterion had been attained, the animal was given a new series of test problems consisting of three new stimuli paired with the nine previously used stimuli or each other in order to generate a new series of stimuli configurations.

\section{Trials to Criterion}

\section{RESUL TS}

All cats and raccoons failed to attain criterion after 4800 trials and testing was discontinued. After 4800 trials they were approximately at chance levels. All monkeys and chimpanzees attained the $90 \%$ criterion and two monkeys and all chimpanzees transferred to the test series at criterion levels. The third monkey scored $80 \%$ correct on the test series. The monkey's mean trials to criterion was 3593.1 , SD $1760_{0} 0$; while the chimpan- 
zee's mean trials to criterion was 2208.0, SD 96.0, a difference significant at the .05 level. From this, it is apparent that the chimpanzees were much more homogeneous in their responding.

In order to compare differences between all four species, the first 48 sessions (2304 trials) were subjected to an analysis of variance. The species effect, sessions effect and species by sessions effect were all significant at the .01 level.

Figure 1 shows the graph of the significant species by trial interaction.

Duncan's multiple range test for correlated and heteroscedastic means (1957) was applied to the data. The means between cats and raccoons was significant at the .05 level, while all other comparisons were significant at the .01 level.

\section{DISCUSSION}

Previous work with sub primate organisms yielded little indication that they had learned oddity. Warren (1960) had one cat attain a one session score at $83.3 \%$, but interpreted this as chance fluctuation. Warren \& Boyd (1951) had two cats attain a one session criterion of $75 \%$ using only two stimulus objects throughout the experiment. It should be further noted that these objects were greatly different in size, a ratio of 10:2. Since Strong's (1965) previous work suggested that learning oddity with six-trial problems apparently generated conflicting response habits, it was felt that the present

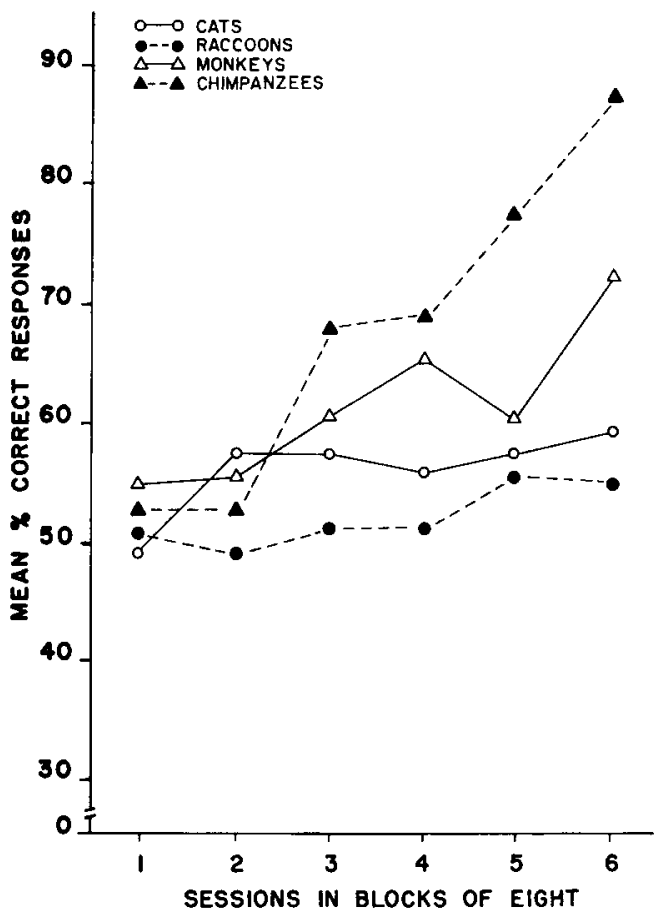

Fig. 1. Trials by species interaction for the first 48 sessions. one trial problem might prove more soluble to cats and raccoons. Apparently, within the conditions set forth in this experiment, true oddity learning may be an impossible task for subprimate organisms.

While the chimpanzees were superior to the monkeys the two species overlapped with the best monkey attaining criterion in 1296 trials, a performance superior to the best chimpanzee. The difference between rhesus monkeys and chimpanzees may be due to emotional rather than intellectual factors since Strong (1965) found that monkeys tested in their home cage on oddity learned more rapidly than in the WGTA。

\section{References}

Braun, H. W. The effects of electroshock convulsion upon the learning performance of monkeys: III. Oddity problems. J. comp. physiol. Psychol., 1952, 45, 585-588.

Bromer, J. A. A genetic and physiological investigation of concept behavior in primates, Unpublished doctoral dissertation, University of Wisconsin, 1940.

Davenport, R. D., \& Menzel, E. W. Oddity preference in the chimpanzee. Psychol. Rep., 1960, 7, 523-526.

Duncan, D. B. Multiple tests for correlated and heteroscedastic means. Biometrics, 1957, 13, 164-176.

Ellis, N. R., \& Sloan, W. Oddity learning as a function of mental age. J. comp. physiol. Psychol., 1959, 52, 228-230.

Gardner, L. P., \& Nissen, H. W. Simple discrimination behavior of young chimpanzees: comparisons with human aments and domestic animals. Ped. Sem. J. gen. Psychol., 1948, 72, 145164.

Koronakos, C., \& Amold, W. The formation of learning sets in rats. J. comp. physiol. Psychol, 1957, 50, 11-14.

Lashley, K. S. The mechanism of vision: XV. Preliminary studies of rat's capacity for detail vision. J. gen. Psychol, 1938, 18, 123-193.

Levine, M., \& Harlow, H. F. Learning-sets with one- and twelvetrial oddity problems. Amer. J. Psychol., 1959, 72, 253-257.

Martin, W. E., \& Blum, A. Effects of irrelevant cues on inter-test generalization in discrimination learning of normal children. Psychol. Rep., 1960, 7, 399-404.

Moon, L. E., \& Harlow, H. F. Analysis of oddity learning by rhesus monkeys. J. comp. physiol. Psychol., 1955, 48, 188-195.

Nisson, H. W., \& McCulloch, T. L. Equated and nonequated stimulus situations in discriminations learning by chimpanzees, III, pre-potency of response to oddity through training. $J$. comp. Psychol., 1937, 23, 377-381.

Pastore, N. Discrimination learning in the canary. J. comp. physiol. Psychol., 1954, 47, 389-390.

Robinson, E. W. A preliminary experiment on abstraction in a monkey. J. comp. Psychol., 1933, 16, 231-236.

Strong, P. N., Jr. Learning and transfer of oddity as a function of apparatus and trials per problem. Psychon. Sci., 1965, 3, 19-20.

Warren, J. M., \& Boyd, B. O. Solution of oddity problems by cats. J. comp. physiol. Psychol., 1957, 50, 258-260.

Warren, J. M. Oddity learning in a cat. J. comp. physiol. Psychol., $1960,53,433-434$.

Woodinsky, J., \& Bitterman, M. E. The solution of oddity problems by the rat. Amer. J. Psychol., 1953, 66, 137-140.

\section{Notes}

1. This research was supported in part by Air Force Contract No. 29(600)-2939. Grateful acknowledgement is made to the Comparative Psychology Laboratory personnel at Holloman Air Force Base for their cooperation.

2. Now at Eastern Carolina College. 